\title{
Pacifica Radio e a radiodifusão comunitária nos Estados Unidos ${ }^{1}$
}

\author{
David King Dunaway, PhD \\ Professor do Departamento de Língua \\ e Literatura Inglesa da Universidade \\ do Novo México. Radiodocumentarista \\ premiado por trabalhos como Pete \\ Seeger: how can I keep from singing \\ (2009), Across the tracks: a Route \\ 66 story (2002) e Aldous Huxley's \\ Brave New World (1999). Produziu \\ documentários radiofônicos para \\ emissoras como National Public Radio, \\ Public Radio International, BBC World \\ Service, Canadian Broadcast \\ Company (CBC) e Danish Radio. \\ E-mail: dunaway@unm.edu
}

\section{Tradução: Daniel Gambaro}

Programa de Pós-Graduação em Meios e Processos Audiovisuais da Escola de Comunicações e Artes da Universidade de São Paulo. E-mail: dgambaro@usp.br
Resumo: A Pacifica Radio Network serviu como modelo para a radiodifusão comunitária, introduzindo o patrocínio pelo ouvinte, o guia de programação e importantes técnicas de arrecadação de recursos. Este artigo oferece uma leitura crítica da história da Pacifica Foundation, baseada na teoria social de Max Weber e de Anthony Giddens. No decorrer da segunda metade do século XX, as crises na Pacifica Radio Network foram reportadas ao redor do mundo. Quais são as principais causas dessas tensões? E o que elas podem nos dizer sobre a produção e distribuição de mídia radical orientada para uma comunidade?

Palavras-chave: Pacifica Radio; Teoria da estruturação; Radiodifusão pública; Burocracia.

\section{Pacifica Radio and community broadcasting in the U.S.}

Abstract: The Pacifica Radio Network has served as a template for community broadcasting, introducing listener-sponsorship, the program guide, and key fund-raising techniques. This article offers a critical reading of the Pacifica Foundation's history, based on the social theory of Max Weber and Anthony Giddens. Over the second half of the $20^{\text {th }}$ Century, crises at the Pacifica Radio Network have been reported around the world. What are the root causes of these tensions? And what do they tell us about the production and distribution of radical, community-oriented media?

Keywords: Pacifica Radio; Structuration theory; Public broadcast; Bureaucracy.

\footnotetext{
${ }^{1}$ Este artigo é a versão em português do texto originalmente publicado no Journal of Radio Studies, v. 12, n. 2, 2005, disponibilizado on-line em 16 de novembro de 2009. DOI: 10.1207/ s15506843jrs1202_5.
} 
Pergunta: "Por que as revoluções não são iniciadas por pessoas mais humanas?"

Resposta: "Pessoas humanas não começam Revoluções."

J. L. Goddard, Notre Musique, 2005.

${ }^{2} \mathrm{~N}$. do T.: Originalmente, o autor usou a expressão "today and over the last decade". Entretanto, para facilitar a leitura (o texto foi escrito em 2005), foi utilizada uma construção que evidencia a época a que ele se refere.

\section{Introdução}

A antiga maldição chinesa sobre viver em tempos interessantes se aplica com particular impacto sobre a história da Pacifica Radio. Em Community Radio News, Bruce Theriault, um dos primeiros executivos da National Federation of Community Broadcasters (NFCB), desafiou a rádio comunitária a se voltar para o futuro na internet e "se reinventar, de uma estação de rádio para uma central de mídia comunitária" (THERIAULT, 2000: 13). Este ensaio explora as tensões fundamentais em uma das primeiras centrais comunitárias de mídia do mundo, a KPFA FM Berkeley - e as outras quatro estações em FM da rede da Pacifica Foundation.

O contexto para a história da Pacifica é a emergência da rádio comunitária nos Estados Unidos; hoje e durante a década de $1990^{2}$, os destinos de ambas têm sido tumultuosos. Sua liderança, tanto quanto sua audiência, está envelhecendo. A Corporation for Public Broadcasting (CPB) consolidou suas estações, ceifando as que estavam em áreas rurais (AVERY; STAVITSKY, 2000 apud WITHERSPOON; KOVITZ, 2000). O Congresso continua a atacar o financiamento a rádios público-comunitárias. As estações locais estão sendo engolidas por cadeias estaduais e nacionais, como a KPCC, em Pasadena, que é localmente financiada e programada pela Minneapolis Public Radio. Os intensos debates dentro das rádios comunitárias sobre acesso versus qualidade da formação de audiência foram amplamente resolvidos: o acesso de cidadãos aos microfones nunca foi tão limitado.

Como sou um DJ em nível local e um produtor de documentários em nível nacional, essas tendências não me são abstratas. Comecei a trabalhar na Pacifica ainda no começo dos meus estudos de graduação, em 1971. Descontente com a pouca quantidade de debate intelectual que ressoava fora do campus, eu desci o morro até a KPFA. Ali, havia público para a academia. Entretanto, meu entusiasmo pela radiodifusão não era compartilhado pelos meus professores. Por muitos anos, levei uma vida dupla, como aqueles espiões comunistas dos anos 1950. Durante o dia, eu lia latim e Joyce; à noite, eu tocava Gid Tanner e The Skillet Lickers. Acabei ficando cerca de 11 anos como membro voluntário do quadro da KPFA, a principal estação da Pacifica, trabalhando com música e notícias cotidianas.

Historiadores da radiodifusão pública, como Helen Katz ou Lynne Gross, sugeriram que o "maior e mais persistente problema" (KATZ, 1989) da rádio não comercial era "sua falta de papel claro ou identidade" (GROSS, 1992). Ainda assim, nós, programadores de rádios comunitárias, sabemos bem qual é o nosso objetivo: criar uma identidade pós-tribal com preocupações sociais explícitas: as desigualdades de poder e de gênero; orientação sexual; orientação a descapacitados; ortodoxia espiritual (o oposto de religiões); as reformas de leis sobre drogas leves, sobre discriminação. Essas eram as ambições da programação da Pacifica durante os anos 1970, conforme as tensões dentro da Pacifica Foundation cresciam continuamente.

Trabalhar na KPFA deu substância para reflexões complexas sobre o processo de uma rádio comunitária. De fato, a estação se tornou um popular estudo de caso de rádios comunitárias (DOWNING; 2001; LEWIS; BOOTH, 1989). A rádio comunitária se identifica como um movimento social, mas o seu campo, a radiodifusão, é cercado por montanhas de ganância comercial e cinismo. Na rede da Pacifica, os ideais sociais e aquele cinismo endurecido pelas lutas se misturam de modo inquietante. "Os problemas periódicos da KPFA espelham os próprios problemas da esquerda estadunidense - uma divisão amarga em facções, disputas sobre as estruturas organizacionais, a tendência de transformar conflitos pessoais em divisões políticas" (ALEXANDER, 1993: 1). 
Já em 1954, cinco anos após a Pacifica começar a transmitir, um membro da equipe que estava se desligando comentou:

Em toda a minha vida, eu nunca tinha visto tantos apóstolos do futuro e mulheres emotivas reunidas em uma única organização. E o mais impressionante é a forma como eles se imaginam nos mais altos princípios éticos, quando na verdade se engajam nas mais amorais atividades maquiavélicas. (LAND, 1999: 59)

Os comentários de historiadores são típicos da reputação da Pacifica: "é claro, sendo esta a Pacifica, muitas pessoas estavam lutando contra as outras" (WALKER, 2001: 74); "a Pacifica Foundation continuou sua tradição de brigas internas" (WITHERSPOON; KOVITZ, 2000: 625). Como um ouvinte comentou, depois de certa mudança em um programa: "Esses segredos e disputas internas Bizantinas, e a recusa em descobrir um modo de incorporar a participação dos membros e a comunicação - [isto] eu deploro" (WALKER, 2001: 150).

A história da Pacifica Radio traz uma questão incômoda: por que uma fundação cujo nome e criação são voltados para a paz é um lugar tão pouco pacífico? Do ponto de vista do chão de fábrica, por que o trabalho a serviço de ideais tão altos acaba vindo com faç̧ões e ataques para alcançá-los?

\section{Metodologia}

O estudo da Pacifica Radio é baseado em uma práxis teórica da rádio comunitária, situando seus dilemas centrais no nosso tempo: acesso versus audiência; identidade e programação nacional versus local; governança participativa versus hierárquica; amadorismo versus profissionalismo (DUNAWAY, 2002). O reconhecimento da influência da Pacifica sobre a radiodifusão comunitária é imperativo.

Essa leitura crítica da Pacifica parte das observações participativas de Matthew Lasar (1998b; 1999), Jeff Land (1999), Eleanor McKinney (1966), Dunaway (2002), além de notícias e histórias de rádios comunitárias. A perspectiva teórica é a Teoria da Estruturação, que sugere as formas em que as estruturas de uma organização determinam o seu funcionamento. Essa teoria surge nos trabalhos do sociólogo alemão Max Weber, e foi atualizada por teóricos sociais modernos como Anthony Giddens (1984); Max Weber se tornou uma tendência atualmente, após ter saído de moda nos anos 1980 (KOLBERT, 2004). Uma das predições mais surpreendentes de Weber é a tensão entre a burocracia e a democracia nas organizações: tal burocracia constrói uma elite dentro de uma organização, e esse grupo (e a organização em si) atua para preservar seu status, independentemente da ideologia. Em uma organização como a Pacifica, o radicalismo está enraizado nas pessoas, e não na organização em si. Essa ideia pode ter um grande papel quando se tenta explicar por que a Pacifica sofre contínuos tumultos: a ideologia localista de seus participantes é continuamente sobrepujada pela construção institucional da organização nacional.

Foram oferecidas formas alternativas de enquadrar as divisões na Pacifica. Em Pacifica Radio: the rise of an alternative network, uma conclusão central é que a Pacifica hesitou entre filosofias de radiodifusão: "uma que enfatizava intercomunicação humanista, e outra que advogava a favor do direito fundamental do indivíduo de falar e de ouvir certas ideias" (LASAR, 1999: 229). Em Active radio: Pacifica's brash experiment, a "tensão persistente" da Pacifica é também apresentada como ideológica: um polo (justiça, igualdade, comunidade) tem consistentemente interagido e se debatido com o outro (excelência, liberdade, autonomia) (LAND, 1999: 144).

Alternativamente, eu sugiro que as tensões nas estruturas sobrepõem as diferenças filosóficas e as canalizam em uma guerra de ideologias opostas. Tais tensões estruturais se desdobram em três: 1 ) rivalidades internas (entre as emissoras da rede); 2) pressões externas (algumas das quais recaem sobre radiodifusores dissidentes); e 3) tensões internas à rede, aquelas que viram manchetes. 
Quais são as raízes dessas tensões, e o que elas revelam sobre a produção e distribuição de mídia alternativa? As respostas a essas questões podem ser encontradas na história da Pacifica.

\author{
${ }^{3} \mathrm{~N}$. do T.: Trata-se de um grupo religioso \\ conhecido também como "Religious \\ Society of Friends", cujas origens \\ remontam à Reforma Protestante na \\ Inglaterra, no século XVII.
}

\section{Uma breve história da Pacifica Foundation}

Os fundadores da Pacifica eram pacifistas influenciados pelos Quakers ${ }^{3}$, e identificavam-se com vários grupos culturais de esquerda durante e após a Segunda Guerra Mundial. Seu passado foi largamente documentado por Matthew Lasar (1999) e Jeff Land (1999). Roy Finch e Lewis Hill se opunham ao envolvimento dos Estados Unidos na Segunda Grande Guerra. Graduado em Stanford, Hill possuía uma vasta gama de conexões com aquela coalizão dispersa que, em 1946, surgiu como a Pacifica Foundation, com o propósito de obter uma licença de difusão radiofônica não comercial, orientada para uma visão pacifista.

A origem do nome do grupo é obscura, e provavelmente foi retirado da publicação semanal de pacifistas independentes em tempos de guerra, o Pacifica Views, publicado entre 1944 e 1947 em Glendora, Califórnia (GOLDWATER, 1966).

Os planos de Hill, Finch e seus apoiadores diferiam radicalmente do modelo corrente dos radiodifusores comerciais: Hill imaginava uma estação cuja renda seria provida por seus ouvintes e, assim, dependeria de sua participação ativa, incluindo o voluntariado nas operações e programação da emissora. Desde o início, seria também uma "rádio de microfone aberto" ", derivada das atividades de Hill no American Civil Liberties Union. Escolher o espectro FM, até aquele momento ainda não utilizado, foi uma das razões para o pedido da primeira licença do grupo ser bem-sucedido. Como a tecnologia era nova naquele tempo, na primeira campanha por fundos, a primeira emissora da Pacifica, a KPFA, que foi ao ar em 15 de abril de 1949, teve que vender receptores de FM com as assinaturas.

Hill e seus associados centralizaram seus ideais de rádio comunitária em quatro características: 1) os voluntários participariam ativamente; 2) com relação aos ouvintes, a qualidade seria mais importante que os números; 3) os ouvintes deveriam escutar seletivamente; 4) o pessoal voluntário não constituiria mão de obra barata, e sim uma extensão da comunidade ouvinte (HILL, 1949 apud MCKINNEY, 1996; LEWIS; BOOTH, 1989). Essa era uma resposta ao muito citado dilema do rádio, como apresentado por Bertold Brecht, isto é, sua natureza unidirecional (BRECHT, 1993). O modelo de patrocínio pelo ouvinte (e de levantamento de fundos por meio de anúncios em jornais e promoções durante as transmissões) que a Fundação Pacifica iniciou na KPFA em 1948 é a principal base da televisão pública e do financiamento ao rádio público hoje. Quando estadunidenses participam de maratonas implorando por dólares para a radiodifusão pública, a Pacifica é o grupo a se agradecer ${ }^{5}$.

${ }^{5}$ A primeira maratona para levantar recursos para a radiodifusão pública ocorreu na WBAI, a estação da Pacifica em Nova York, em 1962, seguida de outra, em 1963, na KRAB-FM em Seattle (ALLEN, 1979; WALKER, 2001).

Para além da invenção do patrocínio pelo ouvinte pela Pacifica, estava seu aparato: o departamento de desenvolvimento e o guia de programação (ou folio, como a KPFA o chamava). Hoje, poucas estações públicas de rádio e TV não oferecem um guia para o ouvinte.

A Pacifica também foi a pioneira no etos "alternativo": a rádio comunitária é um paraíso para abordagens não tradicionais à música, à literatura e mesmo à espiritualidade - e para críticas radicais de eventos contemporâneos (LEWIS, 1972; MCKINNEY, 1966). Pacifica foi uma das únicas difusoras nos Estados Unidos a cobrir de forma independente a Guerra do Golfo, por exemplo, em oposição à cobertura em pool do Departamento de Defesa, alimentada pelas Forças Armadas. Por conta dessa independência política, da relutância em aceitar propagandas ou, por muitos anos, subsídios da Corporação para Radiodifusão Pública, a identidade de independência hostil da Pacifica se espraiou em uma identidade mais liberal do jornalismo investigativo ou de guerrilha e numa destemida crítica cultural.

Hill acreditava que os voluntários eram mais que aficionados com uma coleção extraordinária de discos, que eles eram uma extensão da comunidade ouvinte. Como resultado, a Pacifica ofereceu uma rádio acessível antes mesmo que tal 
${ }^{6}$ N. do T.: NPR é o acrônimo usado para identificar a National Public Radio, ou rede de rádio pública estadunidense.

${ }^{7}$ Em 1956, uma pesquisa encomendada pela emissora descobriu que $70 \%$ da audiência da KPFA era composta por graduados (LASAR, 1998).

${ }^{8} \mathrm{~N}$. do T.: Netcasting é a difusão de conteúdo via internet, em modelos de assinatura para download como o podcast. missão tivesse se propagado. Eles levaram a seus estúdios grandes escritores, editores e comentaristas sociais (especialmente da esquerda liberal) e fomentaram um fórum de ideias que ninguém mais queria difundir. Ao fazer isso, possibilitaram que alguns desses iconoclastas venerassem a si mesmos (a seus gostos musical e político). Programas como Democracy Now (https://www.democracynow.org/), hoje, conectam-se com essa tradição e ancoram fortemente suas muitas afiliações.

Nos anos 1950, a programação matinal da Pacifica encontrou suporte no campus Berkeley da Universidade da Califórnia. Tocavam músicas que, de outro modo, não seriam ouvidas por meio das ondas radiofônicas, incluindo artistas da "lista negra" como Pete Seeger e Paul Robeson, e apresentavam os admiráveis comentários destacados sobre artes ou espiritualidade de gente como Alan Watts, Kenneth Rexroth e Lawrence Ferlinghetti. Assim, a primeira programação da Pacifica esteve culturalmente enraizada no movimento Beat de São Francisco. Desde o início, os ouvintes da Pacifica diferiam significativamente dos ouvintes das emissoras comerciais: alta escolaridade, comprometidos com causas sociais, interessados no avant-garde. O financiamento-chave para alcançar essas pessoas veio do Programa para Educação de Adultos da Fundação Ford, em 1952, o que permitiu que a KPFA progredisse financeiramente durante os anos 1950. Apesar do suicídio de Hill, em 1957, a estação sobreviveu e ganhou o Prêmio Peabody por serviços públicos em 1958. A Pacifica Radio definiu um modelo para o rádio artístico de hoje, ao apresentar música clássica, jazz, música folk e étnica - até então nunca ouvidas fora das emissoras étnicas de algumas grandes cidades.

Ao insistir que a qualidade do rádio era mais importante que os índices de audiência, a Pacifica, sem querer, introduziu a radiodifusão pública e comunitária naquilo que seria tanto seu sucesso como sua ruína - a habilidade de alcançar ouvintes com alto nível escolar, muitos dos quais chegavam a ter pós-graduação, com música obscura e comentários; este é aproximadamente o perfil atual dos ouvintes da NPR ${ }^{6}$ (MCCAULEY, $2002)^{7}$. A programação da Pacifica tinha como alvo pequenos grupos de ouvintes desprezados pelas emissoras mainstream - possivelmente o começo (ao lado da "radiodifusão étnica") do microcasting. Entretanto, ao defender os recônditos e o étnico, a KPFA e outras emissoras da Pacifica, na verdade, inovaram em um modelo de programação para uma elite. Se um ouvinte se importasse em saber detalhes sobre as gravações perdidas do bluesman Robert Johnson, ou em ouvir compositores da nova música, como Lou Harrison ou George Antheil, a Pacifica seria o único lugar no dial. Ironicamente, ao buscar patrocínio de ouvintes que se interessavam por uma cultura esotérica, a Pacifica pode ter iniciado o processo de se dirigir a um segmento restrito e mais privilegiado de uma comunidade, o que é o ideal contemporâneo do netcasting ${ }^{8}$ comercial (e, mais e mais, do rádio público urbano e em rede).

As estações da Pacifica, e publicações como Nation e National Guardian (que teve início no mesmo mês que a KPFA), tornaram-se a voz em radiodifusão do desafio radical às políticas governamentais. Apesar de bem conhecidas pelas constantes lutas internas, o que Todd Gitlin (1980: 29) chamou de "táticas de judô da nova esquerda", elas foram a presença cultural contínua da oposição.

Em 1959, a KPFK foi licenciada em Los Angeles; em 1960, a WBAI foi ao ar na cidade de Nova York. Em 1977, na capital Washington, a WPFW se tornou a última emissora incorporada à rede Pacifica Radio. Desde o começo, três tipos de tensões organizacionais emergiram dentro da Pacifica: internas às estações, internas à rede e forças externas.

\section{Tensões dentro das estações}

As tensões internas às estações tinham como foco os formatos e a organização: deveriam ser predominantemente de música clássica ou de belas artes, ou primariamente internacionais? Os voluntários deveriam ter o mesmo poder de opinião que o pessoal assalariado? As decisões gerenciais deveriam ser tomadas de forma hierárquica ou coletiva? A última questão evidenciava uma tensa dualidade de propósito: a Pacifica Radio era dedicada ao ativismo midiático, mas era mormente um movimento social que abria estações de rádio? Ou era primeiro uma rede radiofônica, 
${ }^{9} \mathrm{~N}$. do T.: Dunaway está se referindo, neste trecho, a um estilo musical folk estadunidense, justamente um dos estilos que compunham o "obscuro", "esotérico" ou "hermético" que o autor menciona como grande parte da programação das emissoras da Pacifica. que provia cultura alternativa? Ao longo dos cinquenta anos de sua história, as tensões internas às estações persistiram entre dois grupos de programação principais: os radiodifusores comprometidos em levar ao ar uma perspectiva ideológica de esquerda, e os profissionais de rádio emergentes que tentavam gerenciar estações em cinco dos maiores mercados de rádio do país.

Entre aqueles que chegaram na Pacifica com uma missão, alguns permaneceram para aprender e desfrutar o rádio; outros foram além e iniciaram uma carreira. Este último grupo competia pelos poucos espaços assalariados com jovens recém-treinados em rádio e sêniores que já tinham sua carreira no rádio. Quem escolhia os funcionários que receberiam ordenados, e definia até que ponto se estendiam as responsabilidades dessa equipe, deixava espaço para que houvesse disputas sobre os limitados recursos. Assim, uma tensão básica sempre foi esta, entre amadores dedicados - alguns dos quais gostariam de ser mais que amadores - e profissionais temporários - alguns dos quais queriam ser amadores para se agarrarem ao seu $Z y d e c o^{9}$ e deixar que alguém decidisse por eles sobre governança e o que iria ao ar.

Tais tensões surgiram cedo na história da Pacifica, particularmente em momentos em que havia um influxo de caixa na fundação. Esse foi o caso em 1952, logo após o auxílio da Fundação Ford, quando Lew Hill se viu preso em uma disputa interna por decisões da programação e por cargos em meio aos poderes relativos dos três principais grupos dentro da KPFA (voluntários, funcionários e a diretoria). Destronado como principal líder da Pacifica, ele retomou sua posição apenas para perdê-la novamente em uma série de eventos que o levaram ao suicídio em 1957. Essas tensões dentro da estação "entre pessoal assalariado e voluntários" (LAND, 1999: 84) ressurgiram na KPFA nas greves de 1964 e 1974. Na WBAI, outro levante ocorreu em 1975-1976, quando uma nova administração e direção de programas tentou direcionar a grade da emissora para longe da colcha de retalhos que alocava o tempo da programação conforme os grupos da comunidade. Os voluntários se trancaram no estúdio e transmitiram sua insatisfação - alguns permaneceram trancados na estação por seis semanas (Ibid.). No mesmo período, a KPFA percebeu que transmitia um programa (Farsi Youth Hour) que apenas quatro pessoas na estação conseguiam entender (uma vez que não havia qualquer tradução em inglês). O programa foi descontinuado, mas a Pacifica continuou a construir e desenvolver sua emissora baseada em representações, esforçando-se para atender grupos e locais, um por um. Sucessivamente, acusações de racismo, sexismo ou discriminação etária eram associadas àqueles que se opusessem ao status quo: na Pacifica, o político rapidamente se tornava bastante pessoal.

O veterano da Pacifica Larry Bensky, administrador da KPFA no começo dos anos 1970, reportou um confronto com três grupos radicais lésbicos pedindo (ou exigindo) tempo no ar: "Eu não podia compreender as diferenças entre os grupos - e eles não conseguiam fazer com que eu entendesse suas diferenças", disse em um filme documentário de 2000, KPFA on the air. Os encontros entre as centenas de voluntários da emissora resultavam, regularmente, em tiroteios e ataques pessoais. Chris Koch, diretor de programação da WBAI-FM em Nova York, uma vez comentou:

Sempre tem uma crise - um grande embate de personalidades, uma disputa sobre a função proposta da Fundação, uma demissão ou restrição pontual [...]. A Pacifica não mantém uma fórmula administrativa dinâmica em que essas pessoas [intensas e criativas] possam trabalhar com sucesso. (MCKINNEY, 1996: 36)

Alguns, como Al Partridge, ex-diretor da KPFA, culparam os voluntários - aquelas pessoas intensas e criativas - pelos conflitos na Pacifica. 
primeiro lugar [...]. Enquanto pessoas desse tipo estiverem envolvidas nesta estação, nunca será possível ter um clima relaxado, confortável. Nós atacamos e somos atacados o tempo todo. (LAND, 1999: 63)

Outros culpavam o pessoal, assalariado ou não, e as pessoas com quem eles trabalhavam. Novamente, Chris Koch: "O membro médio da equipe é sufocado por inúmeros detalhes... ele trabalha sob grande pressão, o relógio devora programas tão avidamente quanto os caminhões de lixo de Nova York tragam os resíduos" (MCKINNEY, 1966: 37). Lasar (1999: 228) escreve:

Conforme o tempo progredia, a cultura dissidente da Pacifica Foundation se dispersou, substituída de forma inadequada por aquilo que a rede precisava urgentemente: uma teoria geral de radiodifusão não comercial que priorizasse o ouvir sobre o falar, o reconhecimento sobre o pronunciamento, e a obrigação mútua sobre os direitos individuais.

\section{Tensões externas}

O pano de fundo dessas divisões eram tensões externas: o macarthismo nos anos 1940 e 1950 e as contínuas batalhas contra a censura feita pela Federal Communications Commison (FCC) nos anos 1950 e 1960.

Um exemplo típico dessas investidas foi o boletim anticomunista, Counterattack, fundado por ex-agentes do FBI interessados no crescente negócio da consultoria anticomunista (COGLEY, 1956). Em fevereiro de 1960, o Counterattack citou a tradição da Pacifica em fazer um rádio "perigoso", permitindo que marxistas falassem no ar. Era ainda pior a ideia de patrocínio pelos ouvintes, um "método de geração tão incomum que era em si revolucionário" (LAND, 1999: 73).

As renovações de licenças eram consecutivamente retidas, e a programação da Pacifica, consistentemente monitorada pelo $\mathrm{FBI}$, particularmente depois que um ex-agente do FBI fez um comentário no ar, em 1962, sobre a intimidação a oficiais públicos feita pelo diretor do FBI, John Edgar Hoover. Um resumo dos ataques do governo à Pacifica lista diferentes investigações federais em 1954, 1960, 1962-63, 1970-71, 1973 e 1978 (MCGILLICUDDY, 1979).

Em 1978, um monólogo feito por George Carlin, Filthy words: seven words you can't say on radio or television (Palavras sujas: sete palavras que você não pode falar no rádio ou na televisão), foi transmitido pela WBAI-Nova York, resultando em anos de litígio sobre a definição de obscenidade (WITHERSPOON; KOVITZ, 2000). Naquele tempo, a revista Variety comentou que "a indiscrição real da Pacifica era sua vigorosa oposição à Guerra do Vietnã" (BUHLE; BUHLE; GEORGAKAS, 1990: 550). Nos anos 1970, a Pacifica se tornou um modelo para a radiodifusão comunitária, que "imitava seu menu de música diversificada, pontos de vista dissidentes e criatividade não categorizável”. (WALKER, 2001: 12).

As batalhas legais da Pacifica colocaram em tensão ainda maior os recursos da rede, conforme eram imputados às estações os custos isolados das defesas diante das cortes, soma que alcançou meio milhão de dólares. O FBI e outras agências de

${ }^{10}$ Os processos de 1978 e 1986 abertos sob a Lei de Liberdade de Informação sobre Pete Seeger e Aldous Huxley, por exemplo, revelaram listagens diárias de suas aparições na Pacifica. inteligência mantinham arquivos elaborados sobre todas as emissoras da Pacifica ${ }^{10}$.

\section{Tensões dentro da rede}

A origem das tensões internas à rede é tão estranha quanto a própria rede da Pacifica. Durante a primeira década, todas as tensões estruturais estavam dentro da estação, uma vez que havia apenas uma delas. Assim que a data de lançamento da segunda estação se aproximava, as tensões emergiram. A KPFK-Los Angeles deveria produzir sua própria programação, ou ela seria uma repetidora da KPFA-Berkeley? Em meio às disputas, o então vice-presidente da Pacifica 
Foundation, William Webb, entregou seu cargo, mas a emissora que ele teria desenvolvido ganhou autonomia.

A expansão trouxe uma nova onda de tensões entre a fundação e suas estações; e entre ouvintes-patrocinadores e mesas-diretoras locais, originando a greve geral de 1974-1975 na KPFA. No ano seguinte, instalou-se um confronto entre as mesas-diretoras local e nacional - a local demandando mais autonomia e redução nos pagamentos para apoiar a mesa nacional (KPFA STRIKE, 1974). Como nos lembra Giddens, não são as motivações dos atores em uma estrutura que importam, e sim as tensões entre a produção dessa estrutura e sua reprodução.

As tensões internas à rede aumentaram nos anos 1970, com seu rápido crescimento. Tais problemas derivavam do papel da direção nacional da Pacifica Foundation nas atividades correntes das estações locais. Emergiu a burocracia, desconectada e sem influências do anarcossindicalismo original da fundação (WALKER, 2001: 64).

A Pacifica Foundation detém as licenças de todas as estações e cobra delas uma taxa anual sobre a arrecadação de fundos para amparar o quadro nacional de trabalhadores e os serviços legais, inclusive os assuntos relacionados a licenciamento e legislação. As mesas-diretoras das estações locais recorrentemente contestam as ações da Fundação Nacional, e regularmente reclamam que suas representações na mesa nacional são insuficientes; e que muitas ações tomadas pela mesa-diretora são antidemocráticas e desconectadas das necessidades locais. Rachas e disputas de personalidades emergiram nessas tensões dentro da rede.

Em meados dos anos 1970, a Pacifica Foundation lançou um serviço nacional de notícias, o Pacifica Nightly News e, para complementar seus serviços nacionais, o Pacifica Program Service, a partir da região norte de Hollywood. Projetos desse tipo, bancados pela mesa-diretora, aumentaram significativamente os custos gerais da fundação (e, por extensão, das estações que a financiavam). Como as batalhas legais resultantes da transmissão de Carlin pela WBAI secaram os parcos recursos da Pacifica, as estações locais se posicionaram umas contra as outras. Nos anos 1980, os ambiciosos planos de crescimento da fundação exigiam audiências ainda maiores, uma tendência entre as emissoras públicas (DUNAWAY, 2002).

Em que momento as diferenças entre a mesa-diretora nacional e as estações realmente pioraram? Talvez tenha sido em 1985, quando a Pacifica Foundation assumiu unilateralmente o controle dos subtransmissores das frequências designadas a cada estação, mantendo as receitas para si. Ou talvez tenha sido em 1992, quando a mesa-diretora nacional estabeleceu sua "Estratégia para Programação Nacional", que delegava ao pessoal assalariado a tomada de decisões (FAIRCHILD, 2001). Ou, ainda, em 1997, quando uma nova equipe gerencial decidiu lançar uma iniciativa nova, populista, direcionada aos afro-americanos, para aumentar a audiência da Pacifica? Enquanto algumas estações hesitaram, a nova equipe inseriu consultores antiorganização trabalhista; tentaram iniciar uma regra de programação obrigatória, de modo que todas as estações deveriam transmitir os mesmos programas ao mesmo tempo. O número de membros da mesa-diretora nacional cresceu de três, em 1989, para treze, uma década depois (WALKER, 2001: 157), o que levou a acusações de uma "monstruosidade burocrata". "Essa administração inútil está organizada de cima para baixo, unidirecionalmente, uma maneira completamente inapropriada para uma organização progressista fundada em ideais antiautoritários" (Ibid.), comentou Lerry Bersky, um diretor da KPFA.

Para muitos daqueles que promoviam uma democracia de base dentro dessa grande organização, a gota d'água foi uma reunião da mesa-diretora, em 28 de fevereiro de 1999, quando algumas diretrizes foram modificadas para desqualificar membros das mesas-consultoras de cada estação.

Nos anos 1990, a Pacifica Foundation lançou um programa de comentário noticioso, o Democracy Now. Essa ação se mostrou tão desafiadora ao status quo que o programa acabou sendo removido da sua estação-sede, a WBAI, em 2001, durante uma crise tão severa quanto qualquer outra na tumultuosa história da Pacifica. Uma 
cronologia detalhada desses eventos pode ser encontrada post-script em Pacifica Radio (LASAR, 1999) e Active Radio (WALKER, 2001).

\section{O Big Bang}

Em 31 de março de 1999, o contrato do diretor-geral da KPFA não foi renovado pela mesa-diretora nacional da fundação. Uma ordem de restrição de informação e confidencialidade emitida pelo diretor da fundação, Lynn Chadwick, produziu uma rodada de demissões de programadores, tanto funcionários como voluntários. Apesar de ter sido enquadrada em termos de profissionalização da programação, a controvérsia talvez estivesse centrada em conflitos pessoais. A mesa-diretora nacional afirmou que queria mais ouvintes e um apelo mais amplo, citando a relativa baixa audiência da KPFA dentro do sexto maior mercado de radiodifusão dos Estados Unidos. Críticos da mesa-diretora apontaram que a composição atual tinha, essencialmente, se autoelegido após a mudança de diretrizes em 1999. Correspondências trocadas entre os membros da mesa-diretora indicam que chegou a ser considerada a venda da KPFA, ou da WBAI, para financiar as crescentes demandas da rede por apoio das estações e seus objetivos de mercado ambiciosos. Em julho de 1999, a KPFA foi lacrada e seus funcionários trancados para fora.

Como noticiado no The New York Times, "houve marchas, shows beneficentes, seguranças armados e tiros disparados" (NIEVES, 1999: 29). A administração se rendeu e, em 5 de agosto de 1999, a estação voltou ao ar, gravemente ferida da perspectiva das relações públicas. O mesmo se pode dizer do aspecto econômico: os esforços da mesa-diretora nacional para defender suas ações resultaram em um corte de 5 milhões de dólares no começo do novo milênio.

${ }^{11}$ Essa crítica ocorreu apesar de o primeiro tiro nessa batalha ter sido a demissão do diretor-geral afro-americano da KPFA-Berkeley.

\footnotetext{
${ }^{12} \mathrm{~N}$. do T.: Timothy Leary foi um professor de Harvard e neurocientista, ícone da contracultura nos anos 1960, famoso por defender os benefícios da substância psicodélica LSD. Ele cunhou a frase "Turn on, tune in, drop out", em que "drop out" significaria compromisso consigo mesmo e mudança pessoal.
}

\footnotetext{
${ }^{13}$ N. do T.: Tratam-se de audiências realizadas em 1954, que visavam investigar acusações contraditórias entre o senador McCarthy e o exército estadunidense, por suposta infiltração de comunistas nas Forças Armadas.
}

\section{${ }^{14}$ N. do T.: Escândalo político ocorrido no segundo mandato do presidente estadunidense Ronald Reagan, sobre a facilitação da venda de armas para o Irã por oficiais do governo, com envolvimento do ex-diretor da CIA Robert Gates.}

\footnotetext{
${ }^{15} \mathrm{~N}$. do T.: Dunaway usou a palavra "vitriol" na sentença, e a palavra escolhida é sua tradução direta. No entanto, são outras possibilidades - todas com um efeito irônico - os termos "veneno", "sarcasmo" e "ódio".
}

A Pacifica sempre foi caracterizada por suas relações semiautônomas entre a programação e a administração, fracamente baseadas em um anarcossindicalismo. Isso foi desafiado em 2000, a partir de mudanças de formato determinadas pela mesa-diretora na KPFA-Berkeley, WBAI-Nova York e KPFT-Houston. Os dissidentes da KPFA abriram vários websites para distribuir informações e fofocas sobre essas batalhas. O ponto de virada na campanha ocorreu na primavera e no outono de 2001, quando teve início um boicote de ouvintes-assinantes à Pacifica e à KPFA absolutamente se recusou a iniciar sua campanha semianual de arrecadação de fundos até que uma nova mesa-diretora, eleita democraticamente, tomasse posse (GONZALEZ, 2001).

Nesse momento, as contas de água e de eletricidade se acumulavam na KPFA, a mais antiga e maior entre as cinco emissoras da rede. Para a mesa-diretora nacional, o problema era a falta de cooperação da KPFA em mudar sua programação para atrair uma nova audiência, mais jovem e urbana. Os membros afro-americanos da mesa criticaram as estações locais e seus administradores por serem "homens brancos com mais de cinquenta anos" (NIEVES, 1999: A12) ${ }^{11}$. Na WBAI-FM, uma "rebelião de Natal" aconteceu quando a mesa-diretora nacional "trocou as fechaduras no meio da noite, instalou câmeras de vigilância, colocou seguranças, e então demitiu e baniu cerca de 25 produtores e membros da equipe" (PACIFICA CAMPAIGN, 2001).

Muitos observadores externos assistiram consternados essa implosão da Pacifica Foundation, a espinha dorsal da cultura radical nos Estados Unidos. A fundação tinha formado o novo projeto de mídia popular, cobrindo as manifestações contra a Guerra do Vietnã, o movimento pela liberação feminina, as greves trabalhistas, os Panteras Negras e, virtualmente, qualquer outra causa que despertasse a paixão da esquerda (LEWIS, 1972). Ela transmitiu o drop out de Timothy Leary ${ }^{12}$; Huey Newton organizando grupos de autodefesa armada em Oakland, Califórnia; e as principais audiências políticas, desde Army-McCarthy ${ }^{13}$ até o escândalo Irã-Contras-Gates ${ }^{14}$.

Para a mesa-diretora, era particularmente frustrante a alienação de ex-apoiadores, como Alexander Cockburn (1997: 10): “Os diretores da Pacifica querem obliterar qualquer traço de autonomia em programação regional e impor o mesmo regime insípido de ideologia e programação que tornou a NPR uma estação de rádio medonha". O que escorria nas ruas não era sangue, e sim vitríolo ${ }^{15}$. 
Em janeiro de 2002, a Pacifica Foundation finalmente encerrou a crise ao constituir uma mesa-diretora com maior representação das mesas das estações locais e de ativistas, voltando-se para figuras carismáticas como Eva Georgia, da KPFK-FM, e Amy Goodman, do programa Democracy Now (CARNEY, 2002). A Pacifica sobrevivera a mais um round de suas recorrentes batalhas. Dessa vez, os extremistas de direita não eram o inimigo, e sim uma crise desencadeada por sua própria estrutura. A nova mesa-diretora nacional tinha uma composição maliciosamente democrática; entretanto, carregava como herança os débitos enormes deixados pelas operações de segurança implementadas pela mesa anterior para defender suas posições impopulares. As últimas disputas domésticas na Pacifica Foundation alcançaram uma solução aberta à comunidade. Ainda assim, as tensões fundamentais persistem na estrutura da Pacifica. A seção final deste ensaio tentará analisar como a Teoria da Estruturação pode explicar essas tensões.

\section{A Teoria da Estruturação e a Pacifica Radio}

Como mencionado anteriormente, a sociologia de Max Weber e Anthony Giddens oferece uma explicação sobre os motivos pelos quais a Pacifica é um lugar tão sem paz: sua estrutura organizacional e sua ideologia estão em guerra.

O alemão Max Weber (1864-1920) foi um economista político/sociólogo que estudou como os valores religiosos, as ideologias e indivíduos carismáticos interagiam com a burocracia em grandes instituições. Ele iniciou sua carreira estudando legislação romana, culminando com a definição de métodos para cientistas sociais e com a compreensão da burocracia, autocentrada e aplicada à construção de instituições, como uma força social. A Teoria da organização econômica e social, de 1925 , publicada por ocasião da morte de Weber, somada à coleção de ensaios que publicou, sugerem conexões entre a burocracia emergente na Pacifica e suas disputas internas.

Max Weber desenvolveu sua pesquisa em estudos sobre como o surgimento do capitalismo colidiu com a ética protestante. O modo como as organizações gerenciam seu pessoal - qual o papel deles na tomada de decisões - determina suas características. "Todas as peculiaridades do capitalismo ocidental derivaram seus significados, em última análise, apenas de suas associações com a organização capitalista do trabalho" (WEBER, 1958: 22). Pode parecer esquisito comparar a Pacifica Radio com a antiga Igreja Protestante, mas, como Weber escreve, ambas necessitam da "estrutura racional da lei e da administração. Porque o capitalismo racional moderno precisou não apenas dos meios técnicos de produção, mas de um sistema legal calculável e de administração em termos de regras formais" (Ibid.: 25). De fato, como o historiador da Pacifica, Matt Lasar contou para mim em 2000, "na Bay Area, a KPFA é a coisa mais próxima a uma igreja que os progressistas tinham".

A Teoria da Estruturação sugere maneiras como a estrutura de uma organização determina seu funcionamento. O contexto mais amplo de um sistema capitalista de radiodifusão configura as instituições (independentemente dos pontos de vista que expressam sobre o capitalismo) e diminui a gama de escolhas efetivas de ação para os atores envolvidos. Conforme Hans Gerth e C. Wright Mills (1946: 68) escrevem, "não importa se esses agentes se consideram bretões, highlanders, ou o que seja; suas posições de classe são estritamente determinadas por seus locais e função".

Weber sugere que as grandes estruturas burocráticas - no caso da Pacifica, não aquelas que produziam os programas, mas as que administravam os administradoresinevitavelmente buscam "aumentar a superioridade dos profissionalmente informados por meio da manutenção de seus conhecimentos e intenções em

${ }^{16}$ Basta observar que a necessidade de transparência das ações da mesadiretora nacional esteve no centro das críticas às decisões mais recentes. segredo... nada é tão fanaticamente defendido pela burocracia"16 (Ibid.: 235).

Desde o começo, a Pacifica Foundation foi dominada não apenas pelos ideais anarcopacifistas, mas também pela natureza carismática de seus fundadores; e isso pode ser compreendido em termos weberianos, no contexto da obra pioneira de 
Weber sobre burocracia, carisma e poder. Os líderes da Pacifica frequentemente apoiavam-se em "uma teologia da autonomia pessoal" (LAND, 1999: 35). Lewis Hill, durante muito tempo venerado na Pacifica, manteve sua autoridade em termos weberianos, em virtude de uma missão assumida para ser encarnada em sua pessoa. Larry Yurdin, um ex-diretor da KPFT-Los Angeles, era amado por seus seguidores: "ele basicamente se tornou o deus, se tornou o rei", lembra seu engenheiro (WALKER, 2001: 112). Tais personagens, conforme compreendia Weber, criam uma "aristocracia carismática" que ativam o discipulado e a lealdade pessoal. "O detentor do carisma desfruta de lealdade e autoridade pela virtude de uma missão que, acredita-se, está incorporada nele" (WEBER, 1958: 1117). Ainda assim, uma estrutura institucional baseada no carisma é inerentemente instável. As primeiras declarações internas de Hill sobre os propósitos da Pacifica, "levar um programa de resistência à guerra a um meio de massa" (HILL, 1949 apud LASAR, 1999: 522), foram, em termos weberianos, superadas pelos princípios estruturais e, frequentemente, deformadas além da possibilidade de reconhecimento, conforme as ideias originais declinaram em dogmas e em sacralidade. De modo similar, a filosofia de liberdade de expressão foi deformada, porque os membros da mesa-diretora foram obrigados a fazer um juramento anticomunista (durante uma audiência sobre subversão, no Senado, em 1963), num momento em que a Pacifica lutava por sua sobrevivência após os ataques da direita nos anos 1950 e 1960. "Culturas e instituições alternativas buscam escapar das amarras apertadas do capitalismo, mas mesmo assim elas se enraízam na agenda do mercado", escreve o historiador da Pacifica, Matthew Lasar (1998b: 514). "Alternatividade substituiu o anarcopacifismo" (Ibid.: 541). Tais mudanças, e as periódicas desilusões dos discípulos do líder carismático, jogaram a Pacifica Foundation em contínuo tumulto. Hill aparentemente compreendera algumas das dificuldades em gerar estruturas idealizadas, uma vez que, mesmo antes da primeira estação da Pacifica entrar em operação, ele escreveu sobre a tensão entre "procrastinar para ganhar confiança" (e uma licença da FCC) e "pureza ideológica, a nós tão requisitada, caso o projeto realmente escape ao fim ordinário das causas quando estas são institucionalizadas" (1949 apud LASAR, 1998b: 522).

Anthony Giddens é um teórico social britânico, que modernizou o trabalho de Weber com sua Teoria da Estruturação. Um dos seus primeiros livros foi dedicado a Max Weber (GIDDENS, 1972). Giddens insiste no papel da agência humana sobre o modo como as organizações e as estruturas sociais se reproduzem. As organizações impõem restrições ao comportamento dos indivíduos por meio de suas "sistemidades" ou "estruturabilidade". Tais filosofias políticas das organizações podem estar separadas das demandas que elas fazem aos indivíduos. As burocracias sejam de esquerda, direita ou centro - podem dizer uma coisa, mas as ações serem o oposto, por conta da tensão entre estrutura e intenção:

Dessa forma, a democracia implica não apenas o direito de autodesenvolvimento livre e igualitário, mas também a limitação constitucional do poder (distributivo). A "liberdade do mais forte" deve ser contida, mas isso é uma negação da autoridade - ou isso apenas se torna verdade no caso de anarquismo. Autoridade é justificável até o limite em que reconhece o princípio de autonomia. (GIDDENS, 1994: 186, grifos nossos)

O equilíbrio entre autonomia e autoridade na Pacifica é delicado, porque a autoridade, normalmente, nem sempre requer credenciais, treinamento profissional ou experiência, mas é situacional. Para Giddens, a Teoria da Estruturação é o encontro da teoria social com a questão da ação:

as instituições não apenas trabalham "pelas costas" dos atores sociais que as produzem e reproduzem. Cada membro competente de cada sociedade sabe bastante sobre as instituições daquela sociedade: esse conhecimento não é incidental [...]. Se os atores são considerados tapados culturais [...], com nenhuma compreensão valorável de seu ambiente ou das circunstâncias de suas ações, imediatamente abre-se caminho para supor que seus próprios pontos de 
vista podem ser desconsiderados em qualquer programa prático que possa ser iniciado. (Id., 1984: 124).

${ }^{17}$ N. do T. All Things Considered (http:// www.npr.org/programs/all-thingsconsidered) foi criado em 1971 pela NPR, sendo um dos programas de maior sucesso da história do radiojornalismo norte-americano.
A história da Pacifica é repleta de momentos em que lados opostos foram descartados como "tapados culturais" de uma maneira, para citar Giddens novamente, que desconsiderou seus pontos de vista no programa prático a ser iniciado. O autor sugere que todos os atores sociais, não importa o quão baixo, têm algum grau de penetração na forma social que os oprimem. Para entender a Pacifica Radio e outras grandes instituições de rádio pública contemporâneas, é preciso concordar com Giddens que "a chave para compreender sua ordem social não é a partir dos valores, mas das relações mutáveis entre a produção e a reprodução da vida social pelos seus atores constituintes" (Ibid.: 101).

\section{Considerações finais}

Ainda que a Pacifica tenha sido vítima de sua própria burocracia, ela também demonstrou uma incrível resiliência, perdurando mais que outras mídias de esquerda que surgiram a partir dos anos 1960. Essa longevidade permitiu sua influência na radiodifusão nos Estados Unidos, de maneira pouco reconhecida. A contribuição mais óbvia é o modelo de radiodifusão pública da Pacifica, iniciado no sistema em que o ouvinte patrocinava a emissora, colocado em operação por Lewis Hill e seus associados. Apesar dos formatos de programação variarem entre as estações da Pacifica, todas foram pioneiras em programas de notícias e outros informativos que se valiam de investigações aprofundadas. Não é uma coincidência que, quando a NPR estava definindo o magazine de notícias vespertino o programa de notícias vespertino All Things Considered ${ }^{17}$, eles procuraram produtores e editores veteranos da Pacifica, como Chris Kock, Margot Adler e muitos outros (LASAR, 1999: 228).

Entre suas inovações na programação, a Pacifica fez a cobertura completa e integral dos mais importantes eventos políticos. Transmitir eventos públicos de longa duração, não mediados, é o grande legado da Pacifica, assim como o modelo de programação "colcha de retalhos", que reflete múltiplas comunidades dentro da mesma frequência. Outra contribuição foi a inserção de programação da radiodifusão internacional nos canais estadunidenses. Quem assiste ao Mystery! e ao Masterpiece Theatre, na PBS (Public Broadcasting System, a rede de TV pública), pode se surpreender ao saber que, no começo dos anos 1950, a Pacifica já transmitia regularmente os serviços internacionais da Deutsche Welle, da BBC e da CBC (Canadian Broadcasting Corporation).

Essa lista poderia continuar indefinidamente. A Pacifica Radio também deu origem às feiras da rádio pública, como sua Feira de Artesanato de Natal, e mesmo festivais culturais, como a Feira Renascentista da Califórnia, que até hoje usa o rádio como o principal meio de divulgação para estimular o comparecimento do público. Pense nos modos de arrecadação de recursos do rádio e da televisão públicos, e os responsáveis pela Pacifica visualizaram isso antes.

Talvez a contribuição mais importante e duradoura seja também a mais abstrata: a construção da identidade da audiência como coautora e participante na programação e no gerenciamento. Essa noção de constituição da audiência não como participação do mercado, mas como uma comunidade, está enraizada no idealismo e nos antecedentes de organização comunitária dos fundadores, programadores e administradores da Pacifica.

Por enquanto, retornando à teoria social, uma última citação de Max Weber (1958: 29): 
a menos que ele saiba que possui o fado e o dom de dar a eles expressão em uma maneira artística ou profética.

${ }^{18} \mathrm{~N}$. do T.: De 1949 a 2005. Nesse momento, o presidente dos Estados Unidos era George W. Bush, membro do Partido Republicano. Por isso, mais adiante, Dunaway se refere aos "Estados Unidos republicano".
Por 56 anos $^{18}$, artistas e profetas floresceram na Pacifica. Não está claro se a rede permanece econômica e politicamente viável nos Estados Unidos republicano; também não está certo se ela conseguirá resistir às tendências, dentro do universo da radiodifusão mais ampla, em direção a um formato voltado para a ortodoxia, a uniformidade e o mercado. Se a Pacifica é a madrinha ilegítima das práticas modernas de rádios comunitárias, em suas tensões estruturais se escondem lições profundas e aparentemente inescapáveis para as outras instituições de radiodifusão pública: tensões entre as mesas-diretoras locais e nacional; entre voluntários e funcionários; entre o modelo de "acesso" do amador à radiodifusão, e o som profissional necessário para competir, hoje, pelos dólares do ouvinte; entre transmitir para a mudança social ou para a sobrevivência institucional.

Fecho este ensaio com uma declaração apaixonada de Chris Koch, ex-diretor de programação da WBAl:

As estações da Pacifica foram administradas tão ao acaso, que aqueles que eram verdadeiramente criativos puderam encontrar ali um lugar sossegado, até que eles foram vencidos pelos aborrecimentos de tentar fazer o que é inatingível [...]. Isto é, em certo sentido, a liberdade habitual por padrão.

Os grandes programas foram difundidos apesar de tudo. Produzidos por pessoas em meio a crises, em gravadores de fita que falhavam, com fitas tão velhas que se partiam ao tocar.

Então, por alguns momentos, houve uma relação inesperadamente intensa entre as pessoas na fita e a audiência que a ouvia em casa - uma magia criada pelo diretor do programa. Havia comunicação. Isso nunca aconteceu em outro lugar, seja no rádio ou na televisão. (KOCH, 1966: 38-39)

\section{Referências}

ALEXANDER, N. What's causing static at KPFA?. News for a People's World, Berkeley, v. 1, n. 3, p. 3-5, abr. 1993.

ALLAN, P. J. The first 30 years. KPFA Folio, Berkeley, CA, v. 31, n. 3, p. 1, mar. 1979.

BERGER, P. L.; LUCKMANN, T. The social construction of reality: a treatise in the sociology. Garden City: Anchor Books, 1967.

BRECHT, B. The radio as an apparatus of communication. In: STRAUSS, N. (Ed.). Radiotext(e): special issue of Semiotexte, Nova York, v. 6, n. 1, p. 15-17, 1993.

BUHLE, M. J.; BUHLE, P.; GEORGAKAS, D. (Eds.). Pacifica Foundation. In: Encyclopedia of the American Left. Champaign: University of Illinois Press, 1990.

CARNEY, S. A KPFK pledge to listen to listeners. Los Angeles Times, Los Angeles, jun. 7, 2002. Disponível em: <http://lat.ms/2gGP3Wv>. Acesso em: 25 set. 2017.

COCKBURN, A. Pacifica Nightmare. The Nation, Nova York, v. 264, n. 20, 10.

COGLEY, J. Report on blacklisting II: radio-television. Nova York: The Fund for the Republic, 1956.

DOWNING, J. Radical Media: rebellious communication and social movements. Thousand Oaks: Sage, 2001. 
DUNAWAY, D. Community radio at the beginning of the $21^{\text {st }}$ century: commercialism vs. community power. In: JANKOWSKI, N. W.; PREHN, O. (Eds.). Community media in the information age. Cresskill: Hampton Press, 2002. (Hampton Press Communication Series: Communication and Participation).

FAIRCHILD, C. Community radio and public culture: being an examination of media access and equity in the nations of North America. Cresskill: Hampton, 2001. (Hampton Press Communication Series: Communication and Participation).

FORCADE, T. (Ed.). Underground press anthology. Nova York: Ace Books, 1972.

GERTH, H.; MILLS, C. W. (Eds.). From Max Weber: essays in sociology. Nova York: Oxford University Press, 1946.

GIDDENS, A. Sociology of Max Weber. Londres: British Sociology Association, 1972. . The constitution of society: outline of the theory of structuration. Berkeley: University of California Press, 1984.

. The transformation of intimacy: sexuality, love and eroticism in modern societies. Cambridge: Polity Press, 1994.

GITLIN, T. The whole world is watching: mass media in the making and unmaking of the new left. Berkeley: University of California Press, 1980.

GOLDWATER, W. Radical periodicals in America: 1890-1950. New Haven: Yale University Library, 1966.

GONZALEZ, J. Save Pacifica before it's sold. In These Times, Chicago, mar. 19, 2001. Disponível em: <http://bit.ly/2y6xG42>. Acesso em: 25 set. 2017.

GROSS, L, Telecommunications: An introduction to electronic media. Dubuque: William Brown, 1992.

KATZ, H. The future of public broadcasting the U.S. Media, Culture and Society, n. 2, p. 195, 1989.

KPFA on the air. Direção: Veronica Selver. Roteiro: Sharon Wood. Lancaster: California Newsreel, 2000. 1 DVD (56 min), son., color.

KPFA Strike. Pamphlet distributed by strikers. 1974. 1 pamphlet. Particular collection.

$\mathrm{KOCH}, \mathrm{C}$. On working at Pacifica. In: MCKINNEY, E. (Ed.). The exacting ear: the story of listener-sponsored radio, and an anthology of programs from KPFA, KPFK and WBAI. Nova York: Pantheon Books, 1966.

KOLBERT, E. Why work?. The New Yorker, Nova York, nov. 29, 2004. p. 154-160.

LAND, J. Active Radio: Pacifica's brash experiment. Minneapolis: University of Minnesota Press, 1999.

LASAR, M. Hybrid highbrow: The Pacifica Foundation and KPFA's reconstruction of elite culture, 1946-1960. Journal of Radio Studies, Abingdon, v. 5, n. 1, p. 49-67, 1998a.

. Right out in public: Pacifica Radio, the Cold War, and the political origins of alternative media. Pacific Historical Review, Berkeley, v. 67, n. 4, p. 513-542, 1998b.

. Pacifica Radio: the rise of an alternative network. Philadelphia: Temple University Press, 1999.

LEDBETTER, J. Made possible by...: the death of public broadcasting in the United States. Londres: Verso, 1997. 
LEMERT, C. (Ed.). Social theory: the multicultural, global, and classic readings. 2. ed. Boulder: Westview Press, 1999.

LEWIS, P.; BOOTH, J. The invisible medium: public, commercial and community radio. Londres: MacMillan, 1989.

LEWIS, R. Outlaws of America: the underground press and its context. Londres: Pelican Books, 1972.

MCCAULEY, M. Leveraging the NPR Brand: serving the public while boosting the bottom line. Journal of Radio Studies, Abingdon, v. 9, n. 1, p. 65-91, 2002.

MCGILLICUDDY, P. KPFA at 30. Berkeley Monthly, Berkeley, 3 maio 1979.

MCKINNEY, E. (Ed). The exacting ear: the story of listener-sponsored radio, and an anthology of programs from KPFA, KPFK and WBAI. Nova York: Pantheon, 1966.

MILAM, L. W. Sex and broadcasting. San Diego: MHO \& MHO Works, 1988.

NIEVES, E. The battle for Berkeley airwaves rages on. The New York Times, Nova York, jul. 23, 1999. Disponível em: <http://nyti.ms/2i5dTvN>. Acesso em: 25 set. 2017.

THERIAULT, B. Editorial. Community Radio News, [S.I.], v. 13, p. 3, mar. 2000.

TRACEY, M. The decline and fall of public service broadcasting. Oxford: Oxford University Press, 1998.

WEBER, M. The protestant ethic and the spirit of capitalism. Nova York: Scribner, 1958.

WITHERSPOON, J.; KOVITZ, R. A history of public broadcasting. Washington, DC: Current, 2000. 